\title{
SUBJECTIVE WELL-BEING OF INTERNATIONAL STUDENTS IN LATVIAN HIGHER EDUCATION INSTITUTIONS
}

\author{
Olga Skvorcova \\ University of Latvia, Latvia \\ Anna Stavicka \\ University of Latvia, Latvia \\ Indra Odina \\ University of Latvia, Latvia
}

\begin{abstract}
Students' well-being and life satisfaction have been the crucial trends in research and practice over the last decades. Often students, who come to study to another country encounter several challenges in the process of integration in the new host country environment. The article deals with the part of the broader research which aimed at fostering international students' integration in the environment of the host country Latvia. The aim of this article is to explore international students' satisfaction as well as the problems they have encountered in Latvian higher education institutions and thus find out the level of their subjective well-being according to Ryff's (1989) stated indicators: autonomy, environmental mastery, personal growth, positive relations with others, purpose in life, and self-acceptance. The data reveal the average score 5.6 out of highest score 7 and the highest scores are for self-acceptance and positive relations with others. The research also coincided with the beginning of the outbreak of COVID-19 pandemic, thus influencing the number of respondents and representation of the countries in the research sample.

The research was conducted in the framework of the project "Multilingual and Multicultural University: Preparation Platform for Prospective International Students" (No. 1.1.1.2/ VIAA/1/16/019) co-funded by ERDF.
\end{abstract}

Keywords: higher education internationalization, multilingual and multicultural learning space, subjective well-being, support provision.

\section{Introduction}

It is apparent and widely documented that higher education internationalization and the related issues have become one of the most topical trends in education research and practice given that "over 
the past 25 years, internationalization has evolved from a marginal and minor component to a global, strategic, and mainstream factor in higher education" (Knight \& de Wit, 2018: 2).

The data provided by the Central Statistical Bureau of Latvia suggests that Latvia is becoming an attractive study destination. For instance, the number of international students in Latvian HEIs by 2019 were 10148, while by 2014, there were 5255 international students in Latvia, which is roughly half as many as in 2019 and confirms the significant growth rates.

Given that attracting international students and improving statistical numbers to confirm the "growth rates" should never be the aim in itself, these are the issues of quality education provision which constantly emerge with every new and unique "case" within the context of internationalized study environment. Inevitably, many students moving to another country for the study purposes frequently encounter with several challenges within the process of their integration in the new and unique environment of the host country. The studies on the well-being of international students as compared to the local ones confirm that the experience of these student groups differs in many significant ways (Ramia, Marginson, Sawir, 2013: 10; O'Reilly, Ryan, Hickey, 2010; Kell and Vogl, 2010). These are the challenges related to language proficiency, differing academic cultures, financial problems, the lack of sufficient support systems, numerous psychological difficulties (e.g., loneliness), etc. (O’Reilly, Ryan, Hickey, 2010). Provided that such pressures negatively impact the learning outcomes and the education process at large as well as have a detrimental effect on students' well-being (O’Reilly, Ryan, Hickey, 2010), which, in turn, may have long-term negative effects on the well-being of the society as a whole. Apparently enough, international students have much more limited resources to deal with such problems (ibid.) than HEIs or other stakeholders. Therefore, in most cases these are the HEIs which should take responsibility for the multi-dimensional and holistic support provision aimed at fostering successful integration of international student population in their entrusted institutions.

Provided that the nature of the problems addressed within the study framework is very different, it is definitely the case that these challenges should be studied from the interdisciplinary and cross-disciplinary perspective to build a holistic view of the complexity of the multilingual and multicultural learning space. This is the development of the short-term and long-term action plan which should come into forth and be worked on collaboratively engaging the stakeholders at institutional, state, regional and global level.

As previously stated, each of the above-specified challenges should be considered through the prism of the necessity to provide complex solutions 
aimed at building productive learning environment for all the stakeholders (including the faculty, administrative staff and others involved). For instance, the problems associated with the language and or languages of instruction have long been the focus of attention in research and practice. Despite the fact that foreign language proficiency in general and languages as tools for international communication for academic purposes specifically have been one of the most topical research directions within the interdisciplinary and cross-disciplinary study areas for several decades (also in Latvia), many issues within this field still need elaboration. It is apparent that language is the key communication tool as well as the main bridge between different cultures (Ramia, Marginson, Sawir, 2013; O'Reilly, Ryan, Hickey, 2010). Therefore, it is not only the question of being able to learn fast and adjust rapidly, but also it is the issue related to the support provision aimed at equipping the learners with the advanced foreign language proficiency to be able to use it not only as a communication tool to "survive" with, but also the effective tool for functioning beyond the "basic needs", as "many international students face the challenge of constructing complex ideas and arguments in the language they are still learning" (Ryan, 2013: 43). It is true that working between two languages is "not only time-consuming but intellectually challenging" (ibid.). These are many language aspects that may hinder the learning process - difficulties related to the necessity to deal with different accents, idiomatic expressions (O'Reilly, Ryan, Hickey, 2010) as well as idiolects alongside with other issues encountered when being involved in the study programmes with a foreign language as a medium of instruction. This partly explains why language barriers are frequently mentioned as the most significant obstacle within the multilingual and multicultural learning space. As concerns the knowledge of a local language, it also adds to the well-being when being in a new environment (Kell and Vogl, 2010). However, given that the Latvian language is generally classified as "uncommon language", it is, unsurprisingly enough, not among the popular languages studied as a foreign language in most countries worldwide.

However, as previously stated, these are not only language difficulties which are most significant in the process of international students' integration in the new environment. International students often encounter challenges adjusting to social and educational expectations - "cultural differences both educational and social - create other difficulties and can lead to students becoming isolated" (Ryan, 2013: 43). All these differences have direct impact on academic performance. International students frequently report "feeling pressure to do well when studying abroad" (O'Reilly, Ryan, Hickey, 2010: online), which may partly be rooted in the claim that "the academic needs of international students are often poorly understood within 
institutions" (ibid.). Nevertheless, given the complexity of the phenomena of an "international student" and "internationalized study environment", the institutional "responsibility" may not be the only or the key reason why students fail to adjust to a new situation. For instance, the challenges which may not be directly associated with the study process itself could be the indirect reason for poor academic performance. International students are frequently reported to have problems with building relationships or friendship with local students, since local students tend "to self-segregate" and see "no need to move out of their comfort zone" (Ramia, Marginson, Sawir, 2013: 11). This only hinders the formation of "positive experience", which was set as a focus within the present study framework.

Being led by the assumption that research and practice within a HEI should be substantiated in its mission and vision and articulating one of the underlying aims generally put forward at the institutional and state level (e.g., "all services provided by a HEI should be managed in order to enhance the quality expected by the client (student)" (Roga, Lapina, Müürsepp, 2015: 926)), the study aimed to explore the subjecting well-being of international students enrolled in higher education study programmes in Latvian HEIs, in order to build the basis for the elaboration of the existing practices within support provision in view of the higher education internationalisation. It should also be highlighted that the research implementation procedure has coincided with the outbreak of COVID-19 pandemic, which led to the necessity to adjust the project implementation procedure. Moreover, it has led to the necessity for further studies given the unprecedented situation and the possible limitations of the previous studies which have not addressed the peculiarities of the integration of international students in a host country environment during in the crisis and post-crisis times.

\section{The Notion and Dimensions of Well-being}

Well-being can be described as positive emotions enhancing psychological feeling well in all human life. When people have a sense of well-being, it means they have a sense of control over their work, life and even destiny; they do not feel stress and are not bored or under pressure. Well-being develops individually and depends on how individuals evaluate their lives. (Mikelsone, Odina, 2016).

At a generalized level, it is important to distinguish between objective and subjective dimensions of well-being (McAllister, 2005; Gasper, 2007).

Objective dimension captures the material and social features of an individual's or community's well-being. This covers the level or wealth, provision of education and health care, infrastructure and so on. It includes 
important questions for society's well-being and can be easily measured at the population level. Similarly, Gasper (2007) describes objective wellbeing as the externally approved, and thereby normatively endorsed, nonfeeling features of a person's life.

Subjective dimension is about a people's evaluation and judgement of their own circumstances: what they think and feel. Subjective well-being is expressed in simple terms like saying, "I feel good" and "I feel happy". It involves two theoretical concepts: hedonic well-being and eudaimonic well-being. Eudaimonic well-being, also known as subjective, means welllived life and the hedonistic approach known as psychological well-being can be explained in terms of pleasure (Svence, 2009; Kahneman, Diener, Schwarz, 2003, Mikelsone, Odina, 2016).

The measurement of well-being can be considered using two broad approaches: objective and subjective measures. Objective well-being measures explain what is required for any individual and then sets out indicators to estimate how far the requirements have been satisfied.

Objective indicators usually measure three main areas:

Economic: household income.

Quality of life: life expectancy, crime rates, educational attainment.

Environment: air pollution, water quality.

Objective well-being measures have been used for many years, but it has been progressively recognized that objective measures on their own cannot measure a people's progress and that subjective measures are also needed (Hicks, 2011).

Subjective well-being measures ask questions to people to assess their own well-being. It argues that the only way to know if someone is happy or satisfied is to ask him or her. Subjective procedure allows for differences in people's values and preferences at professional life and personal level. They are not subjective because they are self-reported, and the question asks a person to rate, how they feel (Hicks, 2011). Unlike objective measures, perceptions are vital and crucial to understanding subjective well-being. The subjective measures are comparable and have helped worldwide to set up programmes to improve the measurement of subjective well-being.

Ryan and Deci (2001) in their Self Determination Theory also point out relative importance of well-being across different cultures especially, the people who work and study in different cultures rather than theirs.

The data of the present research have been analysed based on multidimensional model consisting of six indicators of well-being (Ryff, Keyes, 1995; Ryff, 1995):

- (Self-acceptance) positive evaluation of oneself and one's past which means perceiving oneself and one's personality aspects, as well as one's good and bad virtues, in a positive way. People also show 
positive attitude towards themselves and their past, they are proud of their life.

- (Personal growth) a sense of continuous growth and development as a person is characterized by openness to new experience, the realization of one's potential and behavioural improvement during lifetime. Challenges become important evidence of the growth and one's abilities.

- (Purpose in life) the belief that one's life is purposeful and meaningful - confirms determination, clear understanding of one's goal in life, a sense of direction and confidence in life.

- (Positive relations with others) the ability to build quality relationships with others is seen as empathy, attracting relationship and giving support. It is an interest in and concern to maintain positive relationships with others, even if opinions remain different, or they must give up their positions.

- (Environmental mastery) the ability to affect the world around a sense of mastery and expertise to build one's own environment reveals how people and their activities may affect the processes taking place around. It is mastery and competence to effectively manage and use the environment, to control the complex flow of information. It particularly applies to those activities a person can manage and master. It is demonstrated through relationships with others and in the need for "clear rules of the game".

- (Autonomy) a sense of self-determination is revealed in human judgments and independence, in the ability to resist public pressure and the ability to regulate their own behaviour, as well as the ability to think and act in the selected direction (Mikelsone, Odina, 2016).

\section{Research methodology and Sample}

The article introduces the selected results of a broader research conducted in the framework of the project "Multilingual and Multicultural University: Preparation Platform for Prospective International Students" (No. 1.1.1.2/VIAA/1/16/019) co-funded by ERDF. Within this research, survey was used a research method to explore the well-being of international students in Latvia. The research question was raised: how international students felt studying in higher education institutions of Latvia and what factors influenced their well-being in Latvia. Six aspects of well-being and happiness: autonomy, environmental mastery, personal growth, positive relations with others, purpose in life, and self-acceptance were measured applying the questionnaire as a data collection method, which comprised 25 questions. 18 questions formulated as statements were adapted from 
Carol. D. Ryff's (1989) well-being scale, composed in Likert scale. Each of the six aspects of well-being was measured by the responses to three statements. The response format consisted of 7 possible answers from 1 - strongly agree to 7 - strongly disagree. Later reverse-code was used for 10 statements so that higher scores indicated greater well-being, and then calculated separate subscale scores by summing all items within each subscale. Reverse-scored items were worded in the opposite direction of what the scale was measuring. The research sample comprised 25 international students affiliated to public and private Latvian higher education institutions. The respondents were chosen by a snowball effect method when the first participant recommended next potential respondent. Each respondent was introduced with the research and its aim. Four respondents were known to the researchers. The respondents were 10 females and 15 male students, the average age of the respondents was 20.9 years. As to the nationalities the respondents were Indian (8 people), Uzbek (8 people), Russian (4 people), one German, one Estonian, one Moldovan, one Korean and one Nepalese. 20 respondents studied at Business Higher School Turïba (business administration and tourism and hospitality management) and five at Riga Stradiňš University (medicine). The research was conducted at the beginning of the outbreak of COVID-19 pandemic, thus influencing the number of respondents - many international students were leaving for their home towns and those staying observed social distancing measures, as well as the representation of the research sample - the students that did not manage to return home because of lockdown (India) and the countries that have not been affected too severely by pandemic.

\section{Data and Discussion}

The data of the questionnaire showed that all the respondents came to study to Latvia as one of the European Union countries due to financial reasons: reasonable fees for studies and affordable living expenses. Moreover, it was easy for them to adapt to living in Latvia and most of them were eager to meet new people, learn more about the new culture and traditions. Furthermore, most of the respondents were actively engaged in and enjoyed their studies, since they had an opportunity to interact with other students from all over the world. However, 11 out of 25 students stated they missed their families, and 19 students admitted having financial problems. Therefore, almost half (12) of the respondents were planning to go back to their home countries upon the completion of the study process. Meanwhile, most of the respondents (21) felt happy about their achievements and felt they were making progress towards accomplishing their goals quite often. Finally, all the respondents described their state of 
health as "good". The respondents showed their concerns about four main points when talking about their expectations before arrival to Latvia, such as language problems, differences in culture, ability to use opportunities and build relationship with locals.

According to Ryff's (1989) scale of six aspects of well-being and happiness: autonomy, environmental mastery, personal growth, positive relations with others, purpose in life, and self-acceptance higher scores mean higher levels of well-being. The average score of 25 respondents' wellbeing was 5.6 out of 7. As it has been stated, each aspect of well-being was measured by the responses to three statements. Having calculated and compared scores for each subscale, the conclusion was drawn that students' highest level of well-being related to the Self-acceptance subscale -6 out of 7 (Figure 1). The highest score in self-acceptance subscale was received to liking one's own personality 6.48 ("I like most parts of my personality"); they were satisfied with their own character and did not want to be different. They were less satisfied with the past (5.7 present status and 5.9 achievements out of 7 in two questions), however, despite the various external circumstances they had been able to arrange their life. Selfacceptance is an important indicator because if people realise that they are satisfied with what they are, it helps in developing better understanding not only towards oneself, but the society in general making one more productive and happier.

Lowest levels of students' well-being amongst all six subscales related to the Autonomy (5.3) and the Purpose in Life (5.3) subscales (Figure 1). Concerning Autonomy on one hand, students tended to be influenced by people with strong opinions (score 5.2. out of 7), on the other hand they had confidence in own opinions, even if they were different from the way most other people thought (score 5.7). They just did not reveal their thoughts to others. The lowest score (5.04 out of 7) was received for the statement "I judge myself by what I think is important, not by the values of what others think is important". The findings of this question showed that the respondents were able to resist social pressures to think and act in an independent way. They could evaluate their place of studies and work.

As to the second lowest subscale Purpose in Life (5.3), the lowest score of all was received in expressing the point of view on the statement "I sometimes feel as if I've done all there is to do in life" (score 4.3 out of 7) that might mean the respondents may have doubts on whether they invested the appropriate time into the most significant activities. Answering other two statements, they confirmed they thought about the future (score 6) and they had got a goal (score 5.7). The goal guides life decisions, influences behaviour, shapes action, offers a sense of direction, and creates meaning. For some research respondents, the goal in life is linked with meaningful, 
satisfying work. For others, their goal lies in their responsibilities to their family or friends back at home. Others seek meaning through spirituality or religious beliefs and through prayers in the churches.

The average score of students' well-being level related to the Environmental Mastery subscale was 5.4 out of 7 (Figure 1). The lowest rated statement was about managing the demands of everyday life (score 5.1), although in general, they felt in charge of the situation in which they lived (score 5.3). It might be explained by the obvious fact that being away from home and the usual daily routine lead to additional challenges one needs to resolve encountering them daily and in most common situation. The third statement "I am good at managing the responsibilities of daily life" (score 5.8) confirmed that daily routine might lead to extra effort on behalf of international students as opposed to the local ones. This should be considered and diverse types of support through different channels should be made available.

The average score of students' well-being level related to the Positive Relations with Others subscale was 5.9 out of 7 (Figure 1). The respondents were of quite high opinion about themselves describing themselves as "giving persons, willing to share time with others" (score 6.1), stated they had experienced "many warm and trusting relationships with others" (score 5.9), but they also found it difficult and frustrating to maintain close relationships (score 5.6).

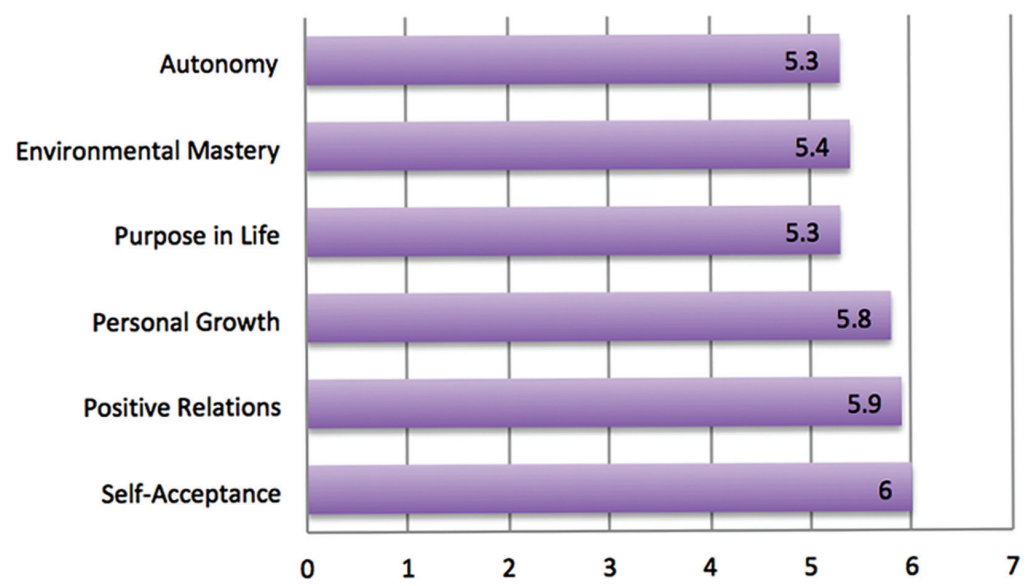

Figure 1. Levels of Participants' Well-being (Skvorcova 2020: 61)

The average score of students' well-being level related to the Personal Growth subscale was 5.8 out of 7 (Figure 1). The highest score (6.2 out of 7) was given for the statement "I think it is important to have new experiences that challenge how I think about myself and the world" which 
was not surprising taking into account that they dared to leave their home country and study abroad. They also admitted that "life has been a continuous process of learning, changing, and growth" (score 6), but at the same time expressed they gave up trying to make big improvements or changes in their life a long time ago (score 5.2). Looking at the findings, it can be concluded that the respondents were interested in their personal development; however, there was a lack of means and lack of time to do so.

\section{Conclusions}

It is apparent that internationalization is one of the major trends in higher education research and practice in the 21st century, since the growth of international students is obviously viewed as a positive development. Globalization is the reality which must be accepted and the strategies to function in the transforming and globalized world should be one of the key underlying work for professionals within all the activity fields.

The study explored the peculiarities of integration of international students in Latvian higher education institutions. The research focus was substantiated by the necessity to evaluate the respondents' satisfaction with their choice to enrol in Latvian higher education study programmes, as well as assess their level of subjective well-being applying the selected methodological approach described in the corresponding subchapter of the paper.

Based on the data obtained in the research framework the conclusion can be drawn that:

- Latvia is viewed as an attractive destination due to having reasonable fees for the studies in HEIs, as well as the living conditions are satisfactory. These data provide the basis for the assumption that Latvia as a study destination can gain further recognition given that the stakeholders recognize certain weak points and elaborate the existing practices to meet the needs of both the prospective international and local students;

- The respondents of the selected research sample were mostly satisfied with their studies and appreciated the opportunity to interact with people belonging to different cultures. However, it should be highlighted that given that numerous studies confirm challenges related to interaction between local and international students, this conclusion might be a coincidence. The expansion of the sample is necessary to provide a holistic picture of the issue under investigation. Nevertheless, another assumption to put forward is that Latvian environment is a relatively positive destination for studies and other activities, which is confirmed by the data revealing that the choice of the country is often predetermined by the indicators within the categories "quality", "expenses" and "comfort" (e.g. "reasonable fees", etc.). 
- The issues of international students' psychological comfort should be put at the foreground at HEIs, given that well-being is one of the significant factors affecting academic performance and daily lives;

- International students frequently report having financial difficulties which may be rooted not only in the fact that they move to another country, but also they make up a specific population in the sense that they start a new stage in their lives when they have to take responsibility for themselves on a daily basis which has not been the case when living with the family. Therefore, specific support, e.g., "life skills" courses may help them deal with the daily challenges in a more productive way. The data obtained add to the basis for the elaboration of the framework aimed at facilitating successful functioning of both local and international students as well as other stakeholders in the multilingual and multicultural environment of present-day Latvia. However, it should be stated that the study limitations are seen in the possible language barrier provided that the data were collected through the English language, which is a second or a foreign language for all the respondents. In addition, the "outsider factor" should be considered.

To conclude, given that the COVID-19 pandemic, which within the months has led to the unprecedented socio-economic crisis severely affecting the higher education sector worldwide, further research to assess and analyse the various impacts of COVID-19 in the short, medium and long term focusing specifically on the support measures necessary in each specific context.

Apparently enough, the COVID 19 crisis will have a significant negative impact on the recruitment of international students. Consequently, the crisis will lead to the urgent necessity to review and elaborate the internationalization strategies of institutions to become competitive in the transforming higher education sector.

\section{References}

Centrālā statistikas pārvalde [Central Statistical Bureau of Latvia] (n.d.). Mobilo studentu skaits Latvijas augstskolās (mācību gada sākumā) [The Number of Mobile Students in Higher Education Establishments in Latvia (at the beginning of the year)]. Available at: https://data1.csb.gov.lv/pxweb/lv/sociala/sociala_izgl_augstsk/IZG311.px/table/ tableViewLayout1/ [Accessed 30 March 2020].

Gasper, D. (2007). Conceptualizing Human Needs and Wellbeing. In: Gough, I. \& McGregor, J. (Eds), Wellbeing in Developing Countries: From Theory to Research (Cambridge University Press: Cambridge). [pdf] Available at: http://repub.eur.nl/ pub/50678/metis_168753.pdf [Accessed 26 September 2020].

Hicks, S. (2011). The Measurement of Subjective Well-being: Paper for the Measuring National Well-being. Technical Advisory Group. Available at: www.ons.gov.uk [Accessed 15 September 2020]. 
Kahneman, D., Diener, E., Schwarz, N. (2003). Well-Being: Foundations of Hedonic Psychology. New York: Russell Sage Foundation.

Kell, P. M., Vogl, G. J. (2010). Global Student Mobility in the Asia Pacific: Mobility, Migration, Security and Wellbeing of International Students. UK: Cambridge Scholars Publishing.

Knight, J., de Wit, H. (2018). Internationalization of Higher Education: Past and Future. Available at: https://www.researchgate.net/publication/327613703_Internationalization_of_Higher_Education_Past_and_Future [Accessed 12 April, 2020].

McAllister, F. (2005). Wellbeing Concepts and Challenges: Discussion Paper, SDRN Discussion paper. [pdf] Available at: http://www.sdresearch.org.uk/sites/default/files/publications/Wellbeing\%20Concepts\%20and\%20Challenges_0.pdf [Accessed 17 September 2020].

Mikelsone, I., Odina, I. (2016). Male Teachers' Well-Being in the Context of Professional Identity. ICLEL 2016: $2^{\text {nd }}$ International Conference on Lifelong Education and Leadership for All, July 21-23, 2016, Liepaja, Latvia: Conference Proceeding Book Sakarya, 2016. P. 19-27, URL: https://media.wix.com/ugd/d546b1_08f6a35b05114b969fb5d41a144 3d619.pdf ISBN 9786056649516.

O'Reilly, A., Ryan, D., Hickey, T. (2010). The Psychological Well-Being and Sociocultural Adaptation of Short-Term International Students in Ireland. Journal of College Student Development, 51(5). Johns Hopkins University Press. Available at: https://muse.jhu.edu/ article/394739 [Accessed 1 May 2020].

Ramia, G., Marginson, S., Sawir, E. (2013). Regulating International Students' Well-being. Great Britain: Policy Press.

Roga, R., Lapina, I., \& Müürsepp, P. (2015). Internationalization of Higher Education: Analysis of Factors Influencing Foreign Students' Choice of Higher Education Institution. Procedia-Social and Behavioral Sciences, 213, 925-930.

Ryan, J. (2013). Cross-Cultural Teaching and Learning for Home and International Students: Internationalisation of Pedagogy and Curriculum in Higher Education. New York: Routledge.

Ryan, R., Deci, E. L. (2001). On Happiness and Human Potentials: A Review of research on Hedonic and Eudaimonic Well-Being', Annual Review of Psychology. [pdf] Available at: condor.depaul.edu/hstein/NYAR.pdf [Accessed 14 September 2020].

Ryff, C. D. (1989). Happiness Is Everything, or Is It? Explorations on the Meaning of Psychological Well-Being. Journal of Personality and Social Psychology, 57(6), 1069-1081. Available at: https://pdfs.semanticscholar.org/0b7c/bc0e7b5946 b39778784a2167019eebd53 e52.pdf [Accessed 18 August, 2020].

Ryff, C. (1995). Psychological Well-Being in Adult Life. Current Directions in Psychological Science, 4(4), 99-103. Available: http://www.jstor.org/stable/20182342? seq $=2 \#$ page_scan_tab_contents.

Ryff, C., \& Keyes, C. (1995). The Structure of Psychological Well-being Revisited. Journal of Personality and Social Psychology, 69, 719-727.

Skvorcova, O. (2020). International Students' Well-being in Latvian Higher Education Institutions. Master's Thesis. Riga: University of Latvia.

Svence, G. (2009). Pozitīvāpsihologiija: laime, optimisms, apmierinātïba ar dzìvi, prieks [Positive Psychology: Happiness, Optimism, Satisfaction with Life, Joy]. Riga: Zvaigzne ABC. 